\title{
ESTEREÓTIPOS NA REDAÇÃO PUBLICITÁRIA
}

\author{
Mariangela B. Fazano Amendola \\ Universidade do Oeste Paulista - UNOESTE. Curso de Comunicação Social, Presidente Prudente - SP. E-mail: \\ mariangelafazano@unoeste.br
}

\section{RESUMO}

O tema deste trabalho está direcionado à análise do discurso. Num primeiro momento, tem-se como base teórica a análise do discurso, no entanto buscar-se-á caracterizar o funcionamento discursivo em textos publicitários, partindo da hipótese de que ações e textos compõem uma prática discursiva ideologicamente confirmada pelas análises. Tem-se assim uma reflexão do uso do estereótipo na Redação Publicitária. O desenvolvimento da pesquisa, fundamentar-se-á teoricamente na Análise do Discurso, à luz dos teóricos: Lippmann, Schaff, Bauman, Bakhtin, Maingueneau, Bosi, Orlandi.

Palavras-chave: Estereótipo. Análise do Discurso. Redação Publicitária.

\section{STEREOTYPES IN THE WRITING ADVERTISING}

\section{ABSTRACT}

The theme of this work is directed to discourse analysis. At first, has as its theoretical basis discourse analysis, however will fetch up to characterize the discursive functioning in advertising texts, based on the assumption that actions and texts comprise a discursive practice ideologically confirmed by the analyzes. Thus has a reflection of the use of the stereotype in Advertising Copywriting. The research development, shall be based theoretically on discourse analysis, in the light of theoretical: Lippmann, Schaff, Bauman, Bakhtin, Maingueneau, Bosi, Orlandi.

Keywords: Stereotype. Discourse Analysis. Writing Advertising. 


\section{INTRODUÇÃO}

O trabalho baseia-se em um estudo realizado por meio de recortes de textos publicitários, caracterizados pela linguagem verbal e não-verbal dos anúncios aqui presentes. Os teóricos forma escolhidos à luz de suas percepções discursivas como apoios reflexivos são eles: Walter Lippmann no que diz respeito ao estereótipo; Adam Schaff discutindo a questão da integração de códigos proporcionada pela linguagem; Zigmund Bauman acerca das concepções sobre "modernidade líquida” ;Mikail Bakhtin sobre a ideologia do signo; Dominique Maingueneau que aborda questões sobre a materialidade da expressão linguística que manifesta o conteúdo da comunicação ; Ecléa Bosi no que tange a opinião e o estereótipo e Eni Orlandi e seus dizeres sobre os processos parafrásticos e polissêmicos da linguagem.

As análises dos três anúncios, pretendem destrinçar seus discursos, a fim de compreender quais são os recursos persuasivos que mais manipulam em seus layouts, apelos e efeitos de sentido em detrimento à criação de estereótipos.

O discurso carrega uma dualidade que é constitutiva da linguagem, isto é, do seu caráter ao mesmo tempo formal e atravessado por entradas subjetivas e sociais.

As primeiras reflexões sistemáticas a respeito dos estereótipos foram apresentadas por Walter Lippmann, um jornalista norte-americano. Ele sugeriu que na vida moderna as pessoas são convidadas a tomar, diariamente, uma série de decisões sobre um conjunto de temas a respeito do qual não possuem qualquer conhecimento. Como esta decisão tem de ser tomada, e de forma rápida, na falta de um repertório informacional adequado que guie racionalmente a decisão, elas terminam por se sustentarem em um conjunto de crenças, compartilhadas amplamente pela sociedade, e sobre as quais não se dispensou qualquer juízo avaliativo.

Ecléa Bosi (2003) diz que a opinião cria estereótipos. Segundo ela, no cotidiano não há como transformar opinião em conhecimento, "a verdade fica sendo a opinião comum" (BOSI, 2003, p.122).

Ao analisar as marcas linguísticas num texto, é possível captar as estratégias interpretativas e a ideologia, impressas nos discursos. O analista do discurso utiliza o texto como unidade de sentido no processo de análise, pois é a partir dele, que captam-se as estratégias de interpretação e as marcas ideológicas no discurso.

Ao compreendermos que o texto é objeto de comunicação e para entendermos as articulações que ocorrem no discurso, é necessário diferenciarmos texto e discurso. 
O texto está no nível material ou o da expressão linguística que manifesta o conteúdo da comunicação; o discurso revela as intenções que estão na materialidade do texto (MAINGUENEAU, 1997).

Como procedimento persuasivo, e por sua vez intencional, a propaganda faz uso do estereótipo (imagem preconcebida de pessoas, coisas (palavras) ou situações). O estereótipo pode ser concebido por crenças, cultura, etnia, religião, classe social, idade, etc.

O criativo recorre subconscientemente, a essa ferramenta por criar identificação, aceitação e confiança no consumidor.

Serão observados os três anúncios abaixo relacionados pelas figuras 1, 2 e 3:

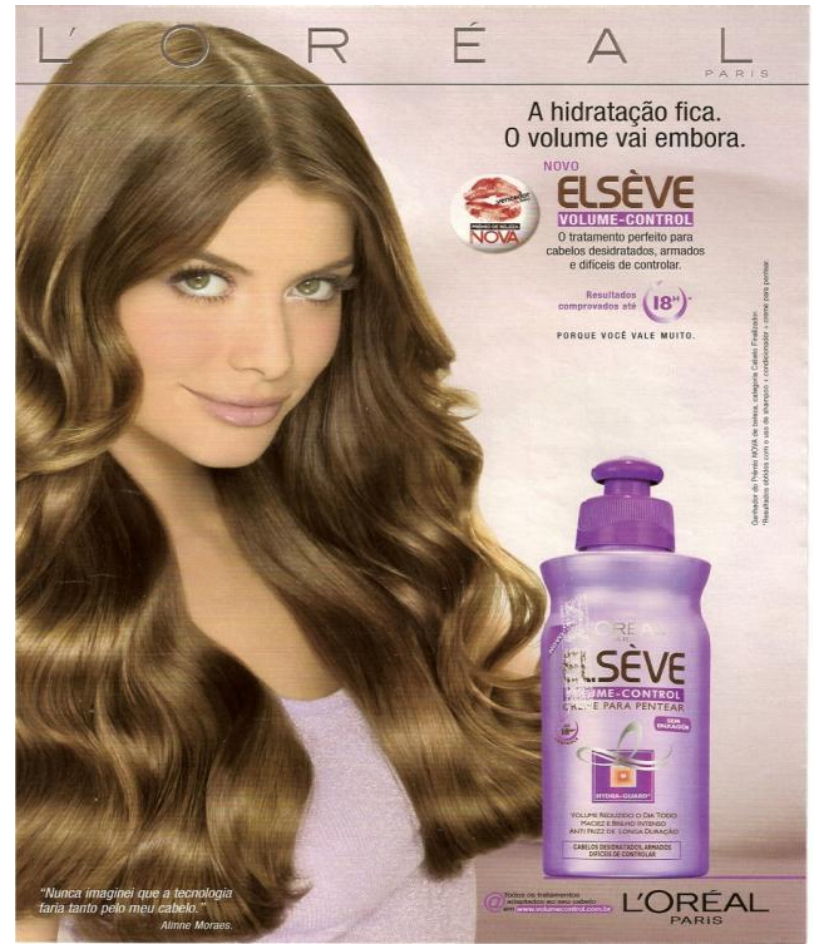

Figura 1. Anúncio do produto Elsève Volume-Control Fonte: Revista Cláudia, o 11, ano 46, novembro de 2007. 


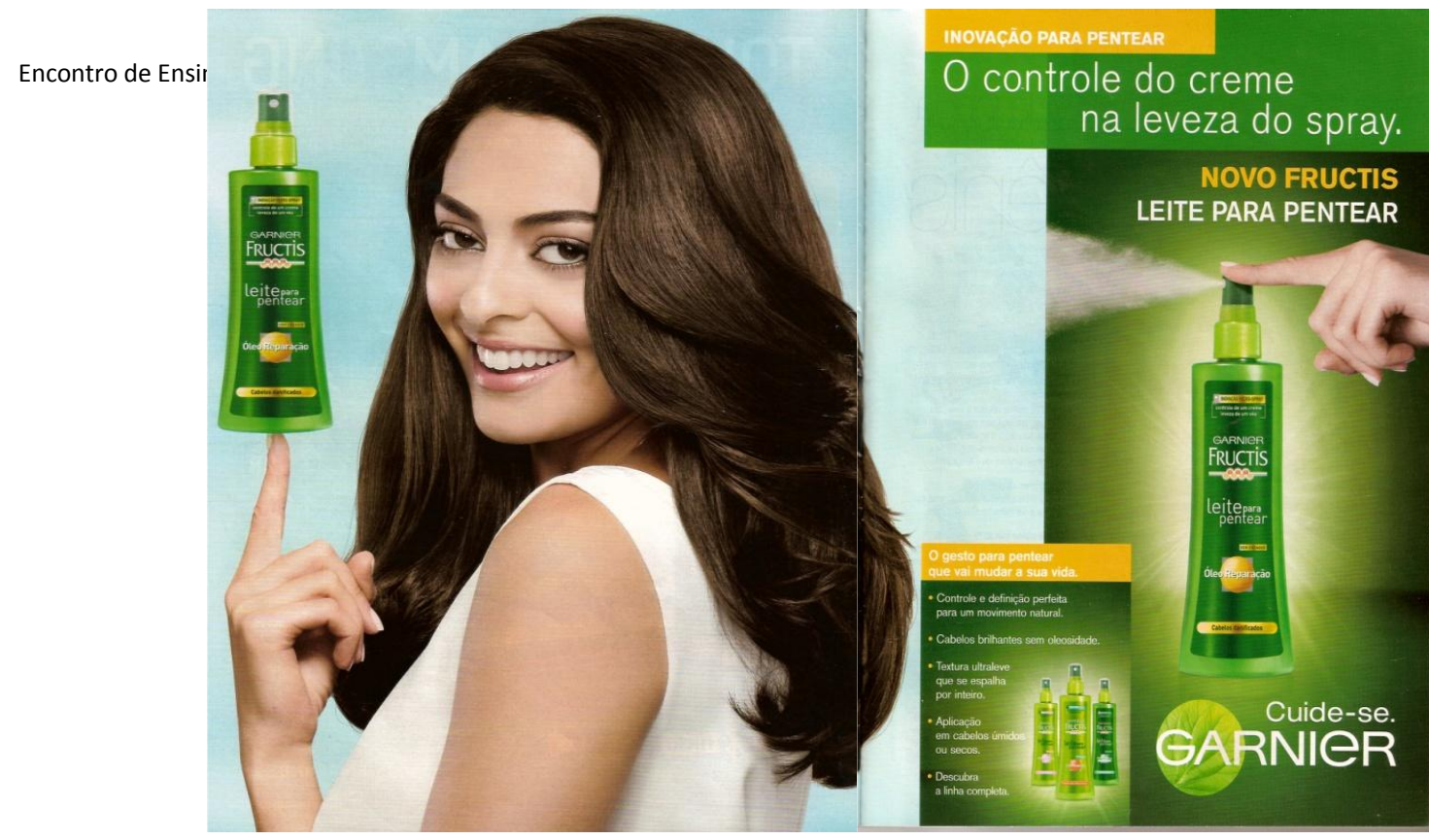

Figura 2. Anúncio do Produto Leite de pentear, da marca Garnier Fructis Fonte: Revista Boa Forma, no 4, ano 25, abril de 2010.

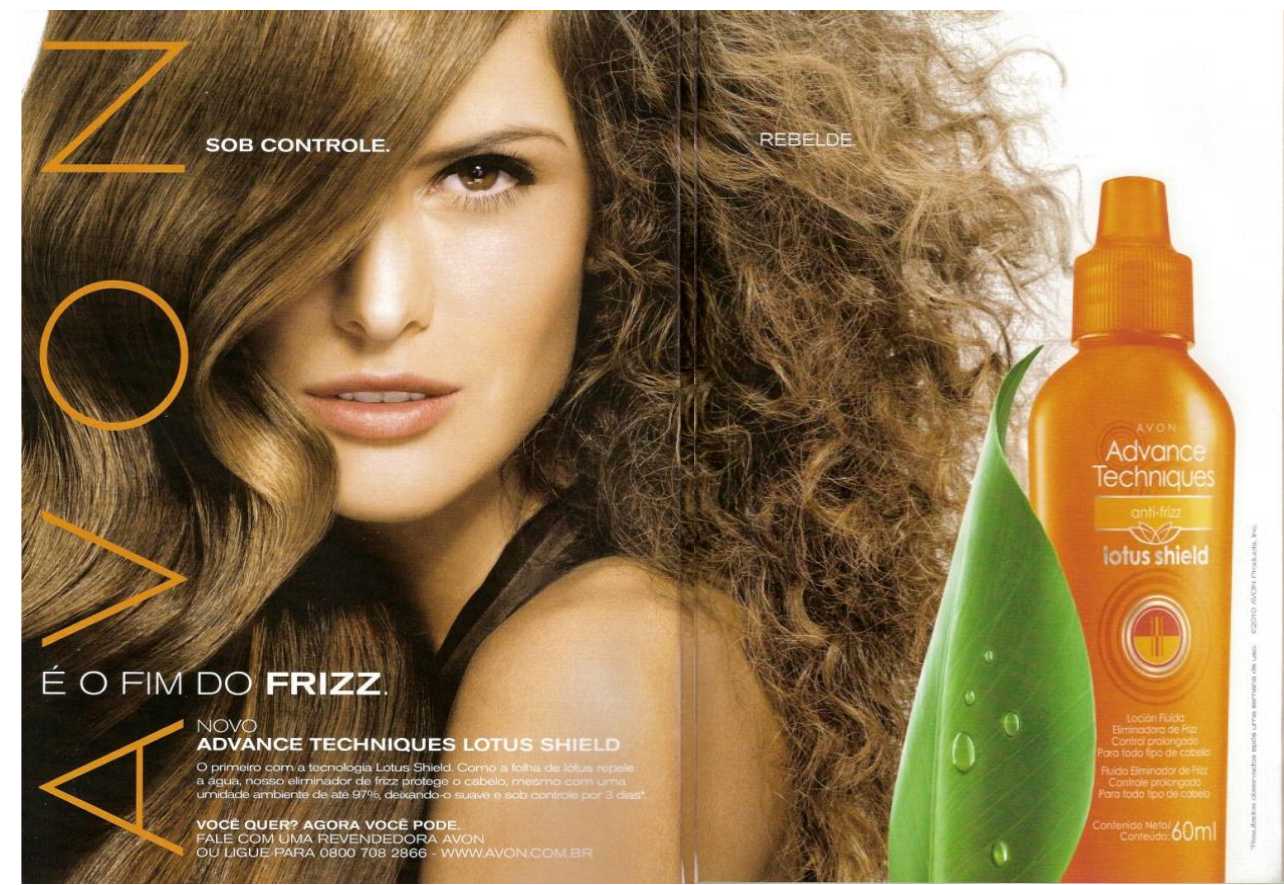

Figura 3. Anúncio do produto Advance Techniques Anti Frizz Lotus Shield da Avon Fonte: Revista ELLE, no 9, ano 23, setembro de 2010.

São três anúncios publicitários do segmento de produtos de beleza para os cabelos, veiculados em revistas femininas de alta vendagem.

Para tanto, convém iniciar a reflexão, descrevendo e caracterizando este discurso tão complexo e repleto de elementos significativos, tanto verbalmente, como visualmente. 


\section{A FUNÇÃO DA PUBLICIDADE}

A função da publicidade é ou deveria ser, primordialmente, o de tornar pública, dar a conhecer a existência de certo produto, serviço ou ideia. Cabe a esta, apontar os diferenciais, as vantagens, desvantagens, utilidades e levar, por diferentes modalidades de manipulação, o consumidor até o ponto de venda.

Quando se analisa a linguagem publicitária quase sempre se fala em manipulação. Sendo assim, o público sabe e espera neste espaço (revista) ser bombardeado por mensagens persuasivas. Todo signo é fenômeno do mundo exterior e tem caráter ideológico. "A consciência é um fato sócio-ideológico". (BAKHTIN; VOLOCHINOV, 1999, p. 35).

Sabe-se que a única função destes textos é fazer circular ideologias dominantes ligadas a produtos ou ideais de beleza.

Porém, a possibilidade ilusória de inclusão nesses ideais, faz com que o leitor invista seu precioso tempo e dinheiro na aquisição de cosméticos, tratamentos estéticos, roupas e acessórios, entre outros.

O sujeito é persuadido ou se persuade a aceitar os valores do grupo social almejado. Por esse motivo, o convencimento quanto ao valor posto em circulação, o valor do objeto ofertado passa a ser primordial. Reside aí o sucesso das marcas, pois o valor agregado ao produto, é a garantia do desejo de consumo.

\section{ANÁLISE DISCURSIVA DOS ANÚNCIOS - CRIAÇÃO DE ESTEREÓTIPOS}

As análises dos três anúncios a seguir, pretendem destrinçar seus discursos, a fim de compreender quais são os recursos persuasivos que mais manipulam em seus layouts, apelos e efeitos de sentido.

Uma vez que estes efeitos de sentido são estabelecidos pela criação de um signo verbal comum às mensagens das 3 campanhas e estereotipados na tessitura do sentido: a palavra CONTROLAR.

Quando falamos em discurso, devemos lembrar-nos da complexidade existente nele. $\mathrm{O}$ discurso carrega uma dualidade que, é constitutiva da linguagem, isto é, do seu caráter ao mesmo tempo formal e atravessado por entradas subjetivas e sociais. Pois segundo Schaff (1974), a linguagem é co-criadora da cultura, os conceitos e estereótipos se cristalizam no tecido social. Ele designa o indivíduo como um ser coletivo, realmente individual (SCHAFF, 1967, p.66).

Os produtos da L'Oréal Paris, Garnier e Avon, são produtos que fazem parte do cotidiano das mulheres modernas pois auxiliam no embelezamento instantâneo dos cabelos, promovendo 
praticidade e autonomia em detrimento de outros afazeres. São cremes, leites e loções fluídas que tratam e ao mesmo tempo controlam volume e frizzado dos cabelos.

O signo linguístico CONTROLAR está presente nos três anúncios, o que evidencia um apelo linguístico muito persuasivo para o público pretendido, um universo de mulheres que desejam cuidar de seus cabelos, sem deixar que isto atrapalhe o corre-corre do dia-a-dia, transformando-se assim num estereótipo de beleza. As mulheres ganharam várias "faces" na publicidade de todos os tempos, estas "faces" são embasadas nos estereótipos femininos de sua época.

Devido às transformações sociais e outros fatores, foi ocorrendo a mudança do estereótipo da dona-de-casa submissa e prestativa para a mulher bela e independente, que trabalha fora e também cuida da casa, pois segundo Vestergaard e Schroder (2000, p.83): "as prioridades femininas mudaram (durante este tempo) da maternidade para a conservação da boa aparência."

Os estereótipos podem se manifestar sob várias formas, mas geralmente encontram-se profundamente enraizados nas tradições culturais de um povo, que são passadas de geração a geração.

São várias as definições e conceitos sobre o termo - e nada mais são que clichês obtidos por estereotipia, conceitos padronizados sobre pessoas, povos, raças, etc. Por isso, o papel da mulher na publicidade está diretamente ligado à sua imagem, refletindo os estereótipos que fazem parte da nossa cultura e reforçando ainda mais a permanência de velhos estereótipos femininos, onde as imagens estereotipadas tornam-se extremamente frequentes nos anúncios publicitários.

Ao serem utilizadas, segundo Vestergaard e Schroder (2000, p.35), "elas estabelecem uma relação entre o produto e uma ideia".

Isso quer dizer que essa ligação entre a imagem feminina e o produto vem de uma conotação a alguma ideia, crença ou pré-conceito já estabelecido na mente das mulheres, onde essa relação entre um certo produto e um estereótipo faz com que o estereótipo seja associado, a partir da sua cultura, imediatamente pela receptora.

A linguagem publicitária também reforça os estereótipos, onde faz-se do texto uma importante ferramenta de persuasão.

O aspecto verbal é colocado estrategicamente nos anúncios publicitários não só para informar o leitor do que está sendo divulgado, mas para influenciá-lo e despertar-lhe o desejo.

O texto publicitário possui algumas características próprias, fazendo com que se seduza o receptor com eficiência. 
Nesse processo de "criação de identidade", a publicidade apresentou as mudanças de valores e conceitos e sabemos que a imagem feminina é frequentemente utilizada nos anúncios publicitários por sua força persuasiva, já que existem vários estereótipos a serem explorados.

A maior parte das mensagens publicitárias dirigidas às consumidoras, não se limita a aquisição de "produtos ditos femininos, como os de moda, perfumaria e cosméticos, como também é responsável pelo consumo da família, como os produtos alimentícios, de limpeza e higiene, eletrodomésticos, produtos destinados às crianças, como os brinquedos, e aos homens, principalmente as roupas". (VESTERGAARD; SCHRODER, 2000). O que pode gerar a ideia préconcebida de CONTROLE.

Apesar dos vários estereótipos femininos existentes na nossa mente (mãe, do lar, esposa, profissional, mulher independente e moderna), a publicidade insiste em reforçar um ponto: a aparência feminina. Segundo Carvalho (1998, p.24), a mulher, seja qual for, deve sempre manter a aparência jovem e bela.

No caso das peças aqui analisadas, o estereótipo CONTROLE, ilustra uma nova maneira de cuidar da beleza, instantaneamente, controlando a natureza dos fios.

O anúncio do produto Elséve Volume-Control da L'Oréal Paris (Figura 01), tem os seguintes elementos verbais:

Título: “A hidratação fica. O volume vai embora." (antítese)

Texto: "Novo Elsève Volume-control. O tratamento perfeito para cabelos desidratados, armados e difíceis de controlar. Resultados comprovados até $18 \mathrm{~h} . "$

Slogan: "Porque você vale muito."

Depoimento de Alinne Moraes: "Nunca imaginei que a tecnologia faria tanto pelo meu cabelo."

Quanto aos elementos visuais, o anúncio opta pela simplicidade do layout com a fotografia da modelo (atriz famosa - Alinne Moraes) disposta ao lado esquerdo, e a fotografia do produto, disposto ao lado direito. Abaixo da imagem do produto, a assinatura da marca.

É uma configuração visual muito simples, o apelo todo é gerado pela mensagem verbal e sustentado pela visual, pois estão perfeitamente ancorados.

O objetivo do anunciante é o de tornar pública a informação, pois, como propõe Schaff (1967), todo pensamento deve se fazer comunicar, para que aja comum acordo e trocas de linguagem. 
O público-alvo que a empresa pretende atingir é o de mulheres, o anúncio encontra-se veiculado na revista Cláudia, publicação amplamente lida por mulheres das faixas etárias entre 20 e 60 anos, que desejam e buscam produtos cada vez mais instantâneos.

Existe no anúncio, a criação do estereótipo de beleza "Controlada" que direciona-se às mulheres modernas que não têm tempo para tratarem dos cabelos.

A mensagem então pretende persuadir seu público, utilizando em seu aparato verbal informações do tipo "a hidratação fica, o volume vai embora", gerando efeito de sentido de instantaneidade, provocado por uma antítese em fica e vai.

O slogan reafirma o estereótipo da mulher moderna que quer ser bela, valorizada e por isto busca o controle de suas atitudes, quando diz: "porque você vale muito".

As palavras de Alinne Moraes, produzem no interlocutor o efeito de sentido de depoimento de autoridade no assunto, valorizando o produto com um Apelo de Autoridade (técnica persuasiva). As imagens tanto de Alinne Moraes, como a da embalagem do produto, identificam a 'cena enunciativa' Maingueneau (1997), em um discurso definitivo e verdadeiro.

Os signos linguísticos "Control" e "Controlar", refletem toda a intenção discursiva deste contexto, pois gera um deslocamento, ao mesmo tempo em que estes signos estão na cena enunciativa parafrasticamente, "re-semantizam" o discurso, oferecendo possibilidades polissêmicas de equilíbrio e domínio, de uma tarefa executada pelas consumidoras em seu cotidiano. "E é nesse jogo entre paráfrase e polissemia, entre o mesmo e o diferente, entre o já dito e o a se dizer que os sujeitos e os sentidos se movimentam, fazem seus percursos, (se) significam." (ORLANDI, 2009, p. 36).

Uma característica muito importante no texto publicitário, raramente citada nas obras pesquisadas, é a utilização de um código comum, que atinja a todas as pessoas, pois mesmo quando o texto é focado em um público específico, cada pessoa tem uma vivência, valores e visões diferentes.

Informações verbais do anúncio da Figura 02:

Título: "Inovação para pentear. O controle do creme na leveza do spray. Novo Fructis Leite para pentear."

Texto: “O gesto para pentear que vai mudar a sua vida.

- controle e definição perfeitas para um movimento natural.

- cabelos brilhantes sem oleosidade.

- textura ultraleve que se espalha por inteiro.

- aplicação em cabelos úmidos ou secos. 
- descubra a linha completa."

Slogan: "Cuide-se."

Os anunciantes de Garnier têm como objetivo colocar no mercado um produto finalizador que atenda expectativas de inovação para propiciar controle dos cabelos.

É um produto que pretende também auxiliar o público-alvo feminino a conseguir "caseiramente" controle nos cabelos com a inovação de ser um leite que está em embalagem spray, o que delimita a intenção de proporcionar às consumidoras algo a mais.

O público-alvo são mulheres da faixa etária entre 20 e 60 anos pois a Revista Boa Forma, onde está veiculado o anúncio, visa atingir um público de mulheres que praticam esporte, trabalham, cuidam dos filhos e ainda desejam ter tempo para se cuidarem.

Assim como no anúncio da Elsève, Garnier modula um estereótipo baseado nas mulheres da atualidade que trabalham fora de casa e precisam de subsídios práticos para manterem a aparência física e portanto, dos cabelos. Aqui, o que chama a atenção é o apelo verbal com relação ao controle e à leveza, ao mesmo tempo em que o produto pretende mostrar verbalmente isso, a imagem da atriz Juliana Paes (Apelo de Autoridade), estampada na página esquerda do anúncio, com a embalagem equilibrada (controlada) nas pontas de seus dedos, ancora-se diretamente ao discurso proposto.

Na página da direita, está o frasco em spray, e a mão da atriz delicadamente ejetando o leite para pentear, como se estivesse fazendo uma demonstração, expressam em sua mensagem não-verbal a percepção de que é possível, por meio deste inovador produto, controlar além do manuseio da embalagem (facilmente, rapidamente), o frizzado do cabelo.

Também na página direta, encontra-se um box com informações sobre o gesto que levará à utilização do produto, e todas as qualidades inovadoras e controladas que ele pode proporcionar.

A cena enunciativa claramente tem o objetivo de produzir o efeito de sentido de um produto que vai solucionar os problemas com os cabelos que toda mulher tem, pois parafraseando o gesto de espirrar o produto, fazemos uma relação direta com elementos polissêmicos de facilidade, praticidade, mobilidade e controle.

O anúncio da Avon exposto na Figura 03, está verbalmente proposto da seguinte maneira:

Título: "Sob controle. Rebelde."(antítese)

Texto: "É o fim do frizz. Novo Advance Techniques Lotus Shield. O primeiro com a tecnologia Lotus Shield. Como a folha de lótus repele a água, nosso eliminador de frizz protege o cabelo, mesmo com uma umidade ambiente de até $97 \%$, deixando-o suave e sob controle por 3 dias. Você quer? Agora você pode. Fale com uma revendedora Avon ou ligue para XXXX." 
Neste anúncio claramente os anunciantes se utilizam de um interdiscurso, o apelo à ciência que é fator preponderante na configuração discursiva. "A 'criação' em sua dimensão técnica é produtividade, reiteração de processos já cristalizados" (ORLANDI, p.37, 2009)

O texto da mensagem explica a matéria-prima do produto a fim de persuadir as consumidoras da verdade instaurada na linguagem.

O título "Sob controle. Rebelde.", utiliza-se da antítese como figura de linguagem, que modula o discurso em uma relação polissêmica com a própria maneira de ser das consumidoras. Pois a polissemia é a simultaneidade de movimentos distintos de sentido no mesmo objeto simbólico (ORLANDI, 2009)

\section{CONSIDERAÇÕES FINAIS}

A palavra controle mais uma vez domina a mensagem, que intencionalmente pretende vender um produto que dome os cabelos, por meio do estereótipo.

A imagem, como em toda comunicação publicitária atual, ancora-se interdiscursivamente ao verbal, sendo uma paráfrase desta cena que se enuncia. Os enunciados dos três anúncios analisados aqui, de forma breve, deixam marcas discursivas muito contundentes; as de que inevitavelmente o público-alvo em questão pretende adquirir controle, domínio e beleza dos cabelos, atrelados à praticidade de produtos cada vez mais avançados e instantâneos.

O conceito criativo ancorado ao estereótipo verbal CONTROLE, perpassa as três mensagens, transformando-se no próprio estereótipo para esta categoria de produtos (sem enxágue).

Isso reafirma o pensamento de Adam Schaff de que o homem é um ser coletivo, realmente individual.

Contudo, convém recorrermos a Zygmunt Bauman, autor que mais tem trabalhado com os determinantes de nosso tempo e mesmo da pós-modernidade.

Ele questiona todo um "espírito de época", vendo no homem contemporâneo um ser desraigado e com grande dificuldade para estabelecer vínculos consistentes. É o homem que pertence ao que ele vai chamar de "modernidade líquida". Com este pensamento podemos refletir que o discurso publicitário, mesmo moldado a toda uma dinâmica discursiva da contemporaneidade, tendencia abordar seus interlocutores de forma muitas vezes agressivas e de ordem imperativa. Podemos chegar a uma hipótese ideológica proposta por Bauman (2001, p. 34):

Nossas escolhas, evidentemente, nem sempre são produto de decisões conscientes. [...] muitas de nossas ações decorrem do hábito e, como tal, não são alvo de escolha ampla e deliberada. Apesar disto, sempre há quem nos relembre 
que nossas decisões nos tornam responsáveis por qualquer resultado que produzam.

\section{REFERÊNCIAS}

BAKHTIN, Mikhail.; VOLOCHINOV. Marxismo e Filosofia a Linguagem. São Paulo: Hucitec, 1999.

BAUMAN, Zygmunt. Aprendendo a pensar com a sociologia. São Paulo: Zahar, 2001.

LIPPMANN, W. Estereótipos. In: STEINBERG, C.S. Meios de comunicação de massa. Trad.: Octavio Mendes Cajado. São Paulo: Cultrix, 1972.

MAINGUENEAU, Dominique. Novas Tendências em Análise do Discurso. São Paulo: Martins Fontes, 1997.

ORLANDI, Eni P. Análise de discurso. São Paulo: Ed. Pontes, 2009.

SCHAFF, Adam. Linguagem e conhecimento. Coimbra: Almedina, 1974.

O marxismo e o indivíduo. Rio de Janeiro: Civilização Brasileira, 1967.

VeStergaARD, T. ; SCHROdeR, K. A Linguagem da Propaganda. Trad. João Alves dos Santos; trad . dos textos publicitários: Gilson Cesar Cardoso de Souza, 3ed. São Paulo: Martins Fontes, 2000. 